\title{
Overtraining and discrimination shift behavior in children'
}

\author{
Louise S. Tighe and Thomas J. Tighe \\ DARTMOUTH COLLEGE
}

\begin{abstract}
After receiving 30 overtraining trials in an initial two-dimensional discrimination, $6 \mathrm{yr}$. old children accomplished a subsequent reversal shift faster than an extradimensional shift. Control Ss trained only to criterion did not differ in speed of learning the two types of shifts. These results are discussed in relation to similar experiments with infrahuman Ss.

\section{Problem}

Previous studies show that mature humans learn a reversal shift (from $S+$ to $S-$ ) more rapidly than an extradimensional shift (from $\mathrm{S}+$ to a stimulus on a previously irrelevant dimension), while the contrary is true for young children and infrahuman organisms (e.g., Kelleher, 1956; Kendler \& Kendler, 1962; Tighe, 1964a). These age- and species-differences are of considerable interest to current theories of development and discrimination (e.g., Kendler \& Kendler, 1962).One approach to the comparative study of shift behavior has been an attempt to eliminate or reduce the differences in shift performance by using special training procedures. Thus, overtraining in an initial discrimination was not found to alter the relative ease of the two types of shift in rats (Tighe, Brown, \& Youngs, 1965) or in monkeys (Tighe, 1964b). In contrast to these results Furth \& Youniss (1964) found that overtraining did enable young children to accomplish a reversal faster than an extradimensional shift. These results support an assumption that there are true species differences in shift behavior which cannot be readily altered by extended training. However, the Furth and Youniss study employed testing procedures which differed in many respects from those used in the comparisons of reversal and extradimensional shifts in infrahuman organisms, and there is evidence which suggests that the facilitating effect of overtraining upon reversal behavior may be strongly influenced by variations in testing procedures. The present experiment seeks to determine if the observed difference in the effect of extended training upon the shift performances of children and infrahuman Ss will also obtain when the same testing procedure is employed with both species.

\section{Method}

Except for the overtraining condition, the procedure, stimuli and apparatus replicated the conditions of Kendler \& Kendler (1959). One hundred and twelve first grade children (average age $6 \mathrm{yr} .8 \mathrm{mo}$.) were first trained to discriminate between pairs of lightweight aluminum tumblers which varied simultaneously in two values of brightness (black and white) and two values of height (tall and short). Thus, the stimuli presented in the initial discrimination on any one trial consisted of one of the following two pairs: (1) a tall (T) white (W) tumbler vs. a short (S) black (B) tumbler, or (2) a TB tumbler vs. an SW tumbler. The Ss first learned a discrimination in which either size (1/2 the Ss) or brightness $(1 / 2$ the $\mathrm{Ss})$ was the relevant dimension. The $\mathrm{S}$ was instructed to pick up one of the tumblers on each trial and was told that if his choice were correct he would find a marble under it. The $\mathrm{S}$ was told that the "game" was to see how soon he could find a marble every time he chose. Following original learning to a criterion the Ss were divided into a criterion group (Group C, $56 \mathrm{Ss}$ ) and an overtraining group (Group OT, $56 \mathrm{Ss})$. Half of the Group C Ss were then given a reversal shift (RS) and the other half were given an extradimensional shift (EDS). For example, if an S had B as the $S+$ during the initial discrimination he could then be given an RS to $\mathrm{W}$ as the S+ or an EDS to $\mathrm{S}$ or $\mathrm{T}$ as the S+. Group OT Ss were similarly treated but only after having received 30 additional training trials beyond criterion on the initial discrimination. This figure represents about $100 \%$ of the mean trials required to complete the original learning. Combinations of positive stimuli in original learning and shift were balanced over groups. During the postshift discriminations the irrelevant dimension was held constant. The Ss were run to a criterion of 9 out of 10 correct responses in the initial discrimination and in the discrimination shifts. Each $S$ was run individually and received the entire sequence of training without interruption or change of instructions. A noncorrection procedure was followed throughout and correct responses were rewarded with marbles. Throughout the training the stimuli were presented according to a prearranged irregular sequence and each $\mathrm{S}$ was assigned to groups and to positive stimuli on a predetermined random basis. At the end of the experiment $S$ was allowed to choose a prize from an assortment which included charms, bubble gum, whistles, Hershey bars, peanuts, and raisins.

\section{Results}

There were no differences among the treatment groups in speed of original learning $(\mathrm{F}<1)$. During overtraining (OT) there was an average of 1.2 errors. Table 1 presents the mean number of trials and errors to criterion during the discrimination shifts for each group. Factorial analysis of variance applied to the trial scores transformed to $\sqrt{\mathrm{X}+.5}$ showed no main effect of overtraining, type of shift, or dimension. However, one 
Table 1. Mean Number of Errors and Trials to Criterion during Shifts (Each subgroup contains $28 \mathrm{Ss}$ )

$\begin{array}{lcc}\text { Group } & \text { Errors } & \text { Trials } \\ \text { C-RS } & 4.71 & 9.23 \\ \text { C-EDS } & 3.54 & 6.50 \\ \text { OT-RS } & 2.04 & 2.96 \\ \text { OT-EDS } & 4.75 & 8.71\end{array}$

interaction, OT $\mathbf{x}$ type of shift, approached significance (F, 3.15; df, 1/104;.05<p< .01). Comparisons of specific group mean trials to criterion were made by the Cochran-Cox test. Ss trained only to criterion did not differ in speed of learning the two types of shift $(p>.70)$ but the overtrained reversal Ss learned faster than the overtrained extradimensional shift Ss $(.02<\mathrm{p}<.05$, twotailed) and tended to learn faster than the criterion reversal shift Ss $(.05<\mathrm{p}<.10$, two-tailed). Similar conclusions result from the analysis of the error measure. This pattern of results indicates that OT selectively facilitated reversal shift.

\section{Diseussion}

This experiment provides further evidence that OT enables young children to accomplish discrimination shifts in a manner similar to that exhibited by mature humans, and it is to be contrasted with the previously cited failures to find an effect of OT on the discrimination shift behavior of infrahuman Ss under the same testing procedures. The species difference in the effect of this training procedure is compatible with the formulation of Kendler \& Kendler (1962) who suggest that relative ease of reversal shift results from the presence of mediating representational responses in the discrimination learning process. The availability of such responses may be assumed to be greater for organisms higher on the phylogenetic scale than for lower organisms. Thus, the OT condition of the present experiment might be interpreted as having afforded the children additional opportunity to develop the appropriate mediating responses, while the fact that a similar OT procedure had no effect on the shift behavior of infrahuman Ss suggests that the mediating processes which enable rapid reversal require more extensive training for their development in animals than is given by such OT procedures. Another interpretation which is permitted by these data is one which stresses the possible importance of the S's sensitivity to the stimulus di- mensions of the discrimination task (Tighe, 1965). Relative difficulty of reversal shift for young children and infrahuman Ss may be deduced from an assumption that these Ss have not yet learned to detect and to utilize the invariant properties (i.e., dimensions) of the task stimuli, but rather respond to the stimulus objects as undifferentiated wholes. According to this view the OT of the present experiment facilitated the isolation by the Ss of the relevant stimulus dimension. The failure of this OT procedure to alter the shift behavior of infrahuman Ss may in part reflect their relatively restricted perceptual experience or an inferior perceptual learning ability as compared with that of children. In this connection, the results of the present experiment may be compared with a study in which children of the same age were tested under the same shift procedures but after having received perceptual pretraining designed to emphasize the independence and the dimensional nature of the stimulus properties involved (Tighe, 1965). This training procedure produced a much more striking selective facilitation of reversal shift than did OT. This observation is consistent with the hypothesis outlined above since the pretraining procedure was explicitly designed to promote the necessary perceptual learning while the OT procedure simply provided further exposure to the stimuli as they were presented in discrete pairs.

\section{References}

FURTH, H. G., \& YOUNISS, J. Effect of overtraining of three discrimination shifts in children. J. comp. physiol. Psychol., 1964, 57, 290-293.

KELLEHER, R. I. Discrimination learning as a function of reversal and nonreversal shifts. J. exp. Psychol., 1956, 51, 379-384.

KENDLER, H. H., \& KENDLER, T. S。 Vertical and horizontal processes in problem solving. Psychol. Rev., 1962, 69, 1-16.

KENDLER, T. S., \& KENDLER, H. H. Reversal and nonreversal shifts in kindergarten children. J. exp. Psychol., 1959, 58, 56-60.

TIGHE, L. S. The effect of perceptual pretraining on reversal and nonreversal shifts. J. exp. Psychol., 1965, in press.

TIGHE, T. J. Reversal and nonreversal shifts in monkeys. J. comp. physiol. Psychol., 1964a, 58, 324-326.

TIGHE, T. J. The effect of overtraining on reversal and extradimensional shifts in monkeys. Paper read at Eastern Psychological Association, Philadelphia, April, 1964b.

TIGHE, T. J.BROWN, P. L., \& YOUNGS, E. A. The effect of overtraining on the shift behavior of albino rats. Psychon. Sci., 1965, 2, 141-142.

Note

1. This research was supported in part by grant GB 1673 from the National Science Foundation to T. J. Tighe. 